\title{
On-Line Strong Cation Exchange $\mu$-HPLC-ESI-MS/MS for Protein Identification and Process Optimization
}

\author{
Thierry Le Bihan, Henry S. Duewel, and Daniel Figeys \\ MDS-Proteomics, Toronto, Ontario, Canada
}

\begin{abstract}
We have developed an on-line strong cation exchange (SCX)-ESI-MS/MS platform for the rapid identification of proteins contained in mixtures. This platform consists of a SCX precolumn followed by a nanoflow SCX column on-line with an electrospray ion trap mass spectrometer. We also used this platform to study the dynamics of peptide separation/ extraction by SCX, in particular to understand the parameters affecting the performance of SCX in multidimensional chromatography. For example, we have demonstrated that the buffer typically used for tryptic digestion of protein mixtures can have a detrimental effect on the chromatographic behaviour of peptides during SCX separations, thereby affecting certain peptide quantitation approaches that rely on reproducible peptide fractionation. We have also demonstrated that band broadening results when a step (discontinuous) gradient approach is used to displace peptides from the SCX precolumn, reducing the separation power of SCX in multidimensional chromatography. In contrast, excellent chromatographic peak shapes are observed when a defined (continuous) gradient is used. Finally, using a tryptic digest of a protein extract derived from human K562 cells, we observed that larger molecular weight peptides are identified using this on-line SCX approach compared to the more conventional reverse phase (RP) LC/MS approach. Both methods used in tandem complement each other and can lead to a greater number of peptide identifications from a given sample. (J Am Soc Mass Spectrom 2003, 14, 719-727) @ 2003 American Society for Mass Spectrometry
\end{abstract}

$\mathrm{P}$ otein expression is a highly regulated process involving multiple genes. Their levels of expression can be regulated at the level of mRNA expression, through degradation pathways, through post-translational modification/processing, through localization, and through secretion. As demonstrated [1], there is not always a clear relationship between the level of mRNA expression and protein expression. Thus, greater insight into protein expression is key to understanding biological processes and diseases. Unfortunately, the equivalent of the genomic gene chip technology is not available for the rapid expression analysis of proteins. Protein expression profiles have been mainly obtained through the combination of 2-D gel electrophoresis and mass spectrometry. Although 2-D gel electrophoresis is a powerful protein separation technique, its combination with mass spectrometry does not always deliver the appropriate sensitivity for the discovery of low-level proteins [2]. In addition, 2-D gel analysis can be biased against the detection of membrane proteins because of solubility issues. Al-

Published online May 21, 2003

Address reprint requests to Dr. T. Le Bihan, MDS-Proteomics, 251 Attwell Drive, Toronto, Ontario M9W 7H4, Canada. E-mail: tlebihan@mdsp.com though many efforts have led to improved processing of various sample types including membrane proteins by 2-D gel analysis, several challenges continue to remain $[3,4]$. Finally and in spite of the tremendous utility of 2-D gels, the technical challenges associated with this technique are limiting its widespread utilization and applicability.

The development of alternative approaches to 2-D gel electrophoresis is vital to the success of proteomics. Efforts have been made to develop "gel free" alternatives for 2-D gel electrophoresis. In general, these approaches consist of isolating proteins from cells or tissues by a protein enrichment method, for example, such as targeting a specific class of proteins [5, 6], using affinity purification approaches [7], and multidimensional protein fractionation strategies [8]. The enriched proteins are then subjected to proteolytic digestion, usually with trypsin, followed by on-line separation of the resultant peptides and identification by mass spectrometry. The most common method used for the on-line separation of peptides is RP chromatography. Multidimensional chromatographic systems based on the combination of ion exchange chromatography, such as strong cation exchange (SCX), followed by RP chromatography have also been developed. Two major 
approaches have been used so far: the MudPIT strategy which involves on-line coupling of the SCX separation with RP chromatography in a SCX-RP-MS/MS platform $[9,10]$, and an off-line SCX fractionation followed by on-line RP-MS/MS [11]. Optimization of the first dimension (i.e., the SCX chromatography) is often neglected due to the time scale of the multidimensional separations.

In the current study, we present our results on the direct and efficient coupling of SCX nanoflow HPLC with mass spectrometry for the rapid and sensitive identification of proteins. To our knowledge, our study represents the first account on peptide separation and identification by SCX-ESI-MS. Huber and Buchmeiser [12] have reported on the use of an on-line SCX-ESI-MS platform to reduce adduct formation during the analysis of nucleic acids. Here, we discuss the limit of detection that can be achieved with the SCX-ESI-MS approach and compare other parameters with on-line RP chromatography. Finally, we present results for the analysis of a complex protein mixture obtained from only $2.2 \times 10^{4}$ human K562 cells.

\section{Material and Methods}

\section{Material}

All reagents used were of the highest quality grade available. Bovine serum albumin (fraction V $>99 \%$ globulin free), rabbit muscle phosphorylase $b(2 \times$ crystallized), ammonium bicarbonate $(>99 \%)$, iodoacetamide, sequencing grade trifluoroacetic acid (TFA), ammonium formate, trichloroacetic acid, and methyltriethoxysilane were obtained from Sigma (St. Louis, MO). Optima grade water and methylene chloride, HPLC grade acetonitrile and methanol, and sodium dodecyl sulfate were purchased from Fisher Scientific (Toronto, $\mathrm{ON}$ ). Dithiothreitol was purchased from Bio-Rad, (Hercule, CA), Suprapur formic acid (98-100\%) was obtained from EM Science Merck KGaA (Darmstadt, Germany), while sequencing grade modified porcine trypsin was purchased from Promega (Madison, WI).

Capillary Picotip columns (360 $\mu \mathrm{m}$ o.d. $\times 75 \mu \mathrm{m}$ i.d.) with a $15 \mu \mathrm{m}$ tip opening and fitted with a borosilicate frit were purchased from New Objective Inc. (Cambridge, MA) and fused silica tubing was from Polymicro technologies (Phoenix, AZ). All connector fittings were purchased from Upchurch Scientific (Oak Harbor, WA) or Valco (Houston, TX). The SCX bulk material used in this study was Polysulfoethyl Aspartamide (5 $\mu \mathrm{m}, 300 \AA$ pore size) from PolyLC, Inc. (Columbia, MD). Zorbax SB-C18 (5 um) RP bulk material was obtained from Agilent Technologies.

\section{Human K562 Protein Extract Preparation}

Human K562 cells were obtained from the ATCC and were cultured in Dulbecco's modified Eagle medium (DMEM) containing 10\% fetal bovine serum and sup- plemented with L-glutamine and non-essential amino acids. Approximately $1 \times 10^{8}$ cells were harvested by centrifugation $(410 \times g)$ and the cell pellet was washed twice with phosphate buffered saline. Total protein was isolated from the cell pellet using TRIzol reagent (Invitrogen Corp., Carlsbad CA) according to the manufactures instructions [13]. The final protein pellet obtained following the TRIzol extraction procedure was solubilized in $1 \%$ SDS $(1 \mathrm{~mL})$. Protein concentrations were determined using the BioRad DC protein assay kit.

A portion of the SDS solubilized protein extract (200 $\mathrm{uL}$, containing $1 \mathrm{mg}$ of total protein) was diluted with water $(500 \mathrm{uL})$ and $75 \mu \mathrm{l}$ of trichloroacetic acid $(1 \mathrm{~g} / \mathrm{mL})$ was added and the sample was maintained at $-20^{\circ} \mathrm{C}$ for $5 \mathrm{~min}$. Precipitated protein was collected by centrifugation $(20,000 \times g, 10 \mathrm{~min})$ at $4{ }^{\circ} \mathrm{C}$ and the supernatant was discarded. The pellet was suspended in $0.5 \mathrm{mM}$ $\mathrm{HCl}$, acetone:methanol (50:50) (300 uL) and following $5 \mathrm{~min}$, the protein was pelleted $(15,000 \times g, 10 \mathrm{~min})$ at $4{ }^{\circ} \mathrm{C}$ and the supernatant was discarded. Cold acetone $(200 \mathrm{uL})$ was added to the pellet and the sample was maintained at $-20{ }^{\circ} \mathrm{C}$ for $10-20 \mathrm{~min}$. The sample was then centrifuged $(20,000 \times g, 10 \mathrm{~min})$ at $4{ }^{\circ} \mathrm{C}$, the supernatant was discarded and the final protein pellet was dried by vacuum centrifugation.

Samples were digested with trypsin essentially as described by Peng et al. [11]. Briefly, the protein pellet from above was suspended in $100 \mathrm{mM}$ ammonium bicarbonate and treated with dithiothreitol $(4 \mathrm{mM})$ at $55{ }^{\circ} \mathrm{C}$ for $30 \mathrm{~min}$. Cysteine residues were alkylated by treatment with iodoacetamide $(12 \mathrm{mM})$ for $1 \mathrm{~h}$ at $37^{\circ} \mathrm{C}$ in darkness. The sample was digested with trypsin overnight at $37^{\circ} \mathrm{C}$ using a trypsin to substrate ratio (wt/wt) of 1:50.

A tryptic digest of bovine serum albumin (BSA) (96 pmol/uL) was prepared as described above. A tryptic digest of phosphorylase $b(57 \mathrm{pmol} / \mathrm{uL})$ was also prepared as described with the exception that the reduction and alkylation steps were omitted and the digest buffer was 100 mM Tris, $\mathrm{pH} 8$.

\section{Capillary LC Precolumn/Column Preparation}

The SCX and RP nanoflow columns were constructed using the Picotip capillary columns (75 um i.d. $\times 7 \mathrm{~cm}$ ). Precolumns were fabricated using fused silica capillary tubing (200 um i.d. $\times 3 \mathrm{~cm}$ ). A frit was created in the precolumn according to the method described by Zhang and Huang [14]. The SCX resin was conditioned prior to packing by treatment with a solution of $0.2 \mathrm{M}$ $\mathrm{NaH}_{2} \mathrm{PO}_{4}, 0.3 \mathrm{M} \mathrm{Na}$ acetate as suggested by the Western Analytical group (http://www.westernanalytical. com). The conditioned resin was then suspended in $1 \mathrm{M}$ ammonium formate, $0.25 \mathrm{M}$ formic acid (FA) and transferred into an in-house built pressure vessel to slurry pack the column and precolumn. The pressure vessel was connected to a high pressure pump (Perkin Elmer series 200 Micropump, Shelton, CT) delivering 0.1\% FA 


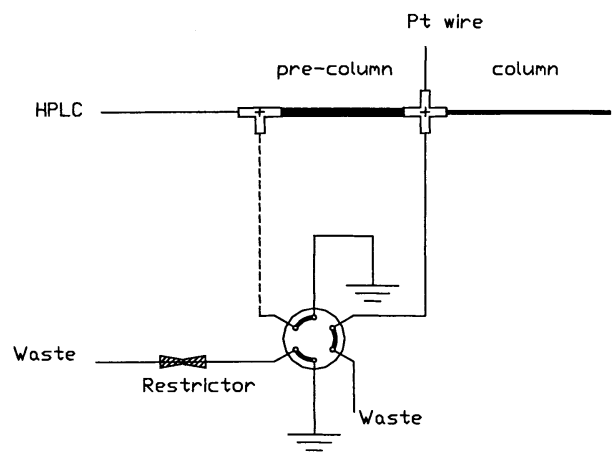

INJECT

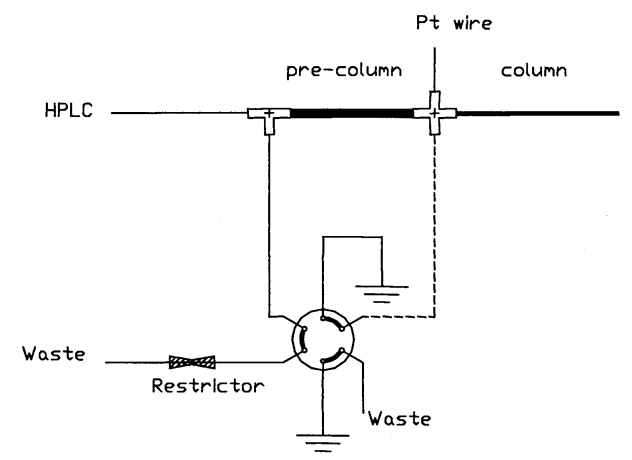

Figure 1. Diagram of the switching precolumn/column system. The divert valve used is a component of the LCQ XP instrument. The dimension of the precolumn is $200 \mu \mathrm{m}$ i.d. $\times 360 \mu \mathrm{m}$ o.d. $\times 3 \mathrm{~cm}$ and the dimension of the column is $75 \mu \mathrm{m}$ i.d. $\times 360 \mu \mathrm{m}$ o.d. $\times 5 \mathrm{~cm}$ with a $15 \mu \mathrm{m}$ tip opening. The restrictor line consisted of a $20 \mu \mathrm{m}$ i.d. $\times 360 \mu \mathrm{m}$ o.d. $\times 15 \mathrm{~cm}$ piece of fused silica. All other connecting capillary tubing was $50 \mu \mathrm{m}$ i.d. $\times 360$ um o.d. fused silica. The configuration used was the same for both on-line SCX and RP applications.

(vol/vol) in water at a maximum pressure of 400 bar. A similar method was used to pack the RP precolumn and capillary column with the exception that the RP resin slurry was prepared in chloroform and the pump delivered acetonitrile.

\section{HPLC and Mass Spectrometry}

All mass spectrometric experiments were performed using an on-line liquid chromatography-tandem mass spectrometry (LC-MS/MS) setup consisting of an Ultimate LC system and Famos autosampler (LC Packings, San Francisco) fitted to a LCQ Deca XP ion trap mass spectrometer (Thermo Finnigan, San Jose, CA) equipped with a modified nanoelectrospray ion source (Protana Engineering, Odense, Denmark). The mass spectrometer was operated in a data-dependent acquisition mode to automatically switch between MS and MS/MS acquisition controlled by the Xcalibur software. A full scan MS spectrum was acquired followed by tandem mass spectra of the three most intense precursor ions present in the MS scan. The temperature of the heated capillary was set at $160^{\circ} \mathrm{C}$ and the capillary voltage at $1.3 \mathrm{kV}$. We replaced the stator on the LCQ diverter valve with one having smaller ports to avoid damage to the stator by the fused silica tubing [15]. The LC/autosampler was fitted with either a NANO-75 and CAP-300 split flow in order to produce flow rates in the range of approximately $0.2 \mathrm{ul} / \mathrm{min}$ and $1-2 \mathrm{uL} / \mathrm{min}$, respectively. For reverse phase chromatography, a gradient elution from water to acetonitrile, each containing $0.1 \%$ FA and $0.025 \%$ TFA, was performed. For SCX chromatography, a gradient from 0 to $1 \mathrm{M}$ ammonium formate in $0.25 \mathrm{M}$ FA was used.

The column configuration is illustrated in Figure 1. Typically, $5 \mu \mathrm{l}$ of the sample to be analyzed is injected onto the precolumn at a high flow rate (ca. $1 \mu \mathrm{l} / \mathrm{min}$ ), with the valve in the load position. During the sample load, the split flow at the front of the precolumn is closed. Once the sample has been loaded and the precolumn washed, the valve switches to the inject position activating the flow splitting at the front of the precolumn, thus reducing the flow rate to the capillary column to $0.2-0.6 \mathrm{ul} / \mathrm{min}$.

\section{Database Searches}

All MS/MS data was searched using MASCOT (Matrix Science, UK) [16] against the NCBI non-redundant (nr) database. Data acquired from analysis of BSA and phosphorylase $b$ were searched against the entire mammalian subset of sequences (NCBInr date 20021114, MASCOT version 1.8). In the case of the samples derived from the K562 protein extract, the MS/MS data were searched against only the homo sapien subset of sequences (NCBInr date 20021114, MASCOT version 1.9) Searches were performed allowing for variable modification on methionine (oxidation, +16 Da) and cysteine (carbamidomethylation, $+57 \mathrm{Da}$ ) residues.

\section{Results and Discussions}

It is generally being accepted that the global study of protein expression provides a higher resolution view of cellular processes than does gene expression. However, the concentrations of individual proteins in cells can span five orders of magnitude while the total number of different proteins expressed number in the thousands [17]. Therefore, any realistic and reliable representation of protein expression will only be possible if more powerful analytical techniques are developed.

Multidimensional chromatography is a potential method that has been developed to address this challenge. Typically, it consists of the sequential chromato- 

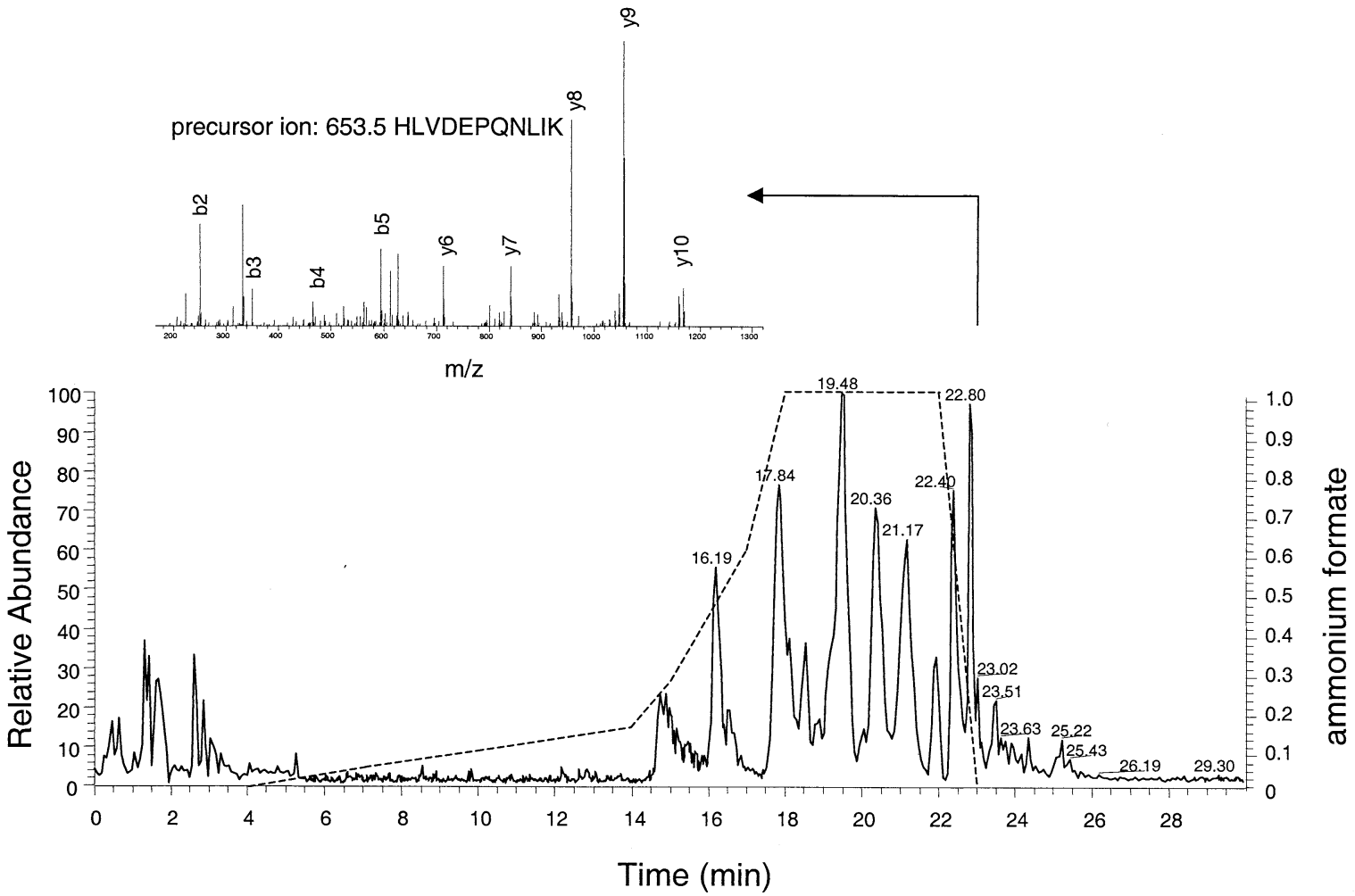

Figure 2. Base peak chromatogram obtained from the SCX-MS/MS analysis of $950 \mathrm{fmol}$ of a BSA digest using a gradient elution. Separation was achieved using a SCX-precolumn coupled to a SCX-capillary column as described in Figure 1. Peptides were eluted using a gradient (indicated by the dashed line) from $0.25 \mathrm{M}$ FA to $1 \mathrm{M}$ ammonium formate, $0.25 \mathrm{M} \mathrm{FA}$. The flow rate was $\sim 400 \mathrm{nl} / \mathrm{min}$. Inset: MS/MS spectrum (with assigned fragment ions) acquired for the ion with $\mathrm{m} / \mathrm{z}=653.5$ and eluting at ca. $22.8 \mathrm{~min}$.

graphic separation of protein digests by strong cation exchange and reverse phase chromatography, as exemplified by the MudPIT approach [9, 10]. On-line multidimensional chromatography poses serious challenges in terms of defining SCX and RP chromatographic conditions that are compatible with mass spectrometry while maintaining chromatographic performances. The optimization of multidimensional separation is often limited either because the first dimension (i.e., the SCX chromatography) is achieved by off-line fractionation [11] or on-line through a step-gradient elution requiring extended analysis times (80-110 $\mathrm{min}$ ) for each elution step [10]. Under these conditions, the SCX elution profile is not accessible, thus rendering optimization of the SCX chromatography difficult. A direct analysis of the SCX separation behavior performed on-line with MS would allow for improved optimization. Furthermore, the direct coupling of SCX with mass spectrometry for the rapid identification of proteins would provide an alternative to RP-LC/MS/MS

To this end, we have developed a sensitive and robust on-line SCX-MS platform. Briefly, the system consists of a SCX-precolumn follow by a SCX column coupled directly to an electrospray ionization mass spectrometer. Details of the column geometry are presented in Figure 1. The chromatographic buffer system used (gradient elution from $0.25 \mathrm{M}$ FA to $1.0 \mathrm{M}$ ammonium formate, $0.25 \mathrm{M} \mathrm{FA}$ ) was developed to be compatible with MS and to provide effective peptide separation.

\section{Standard Protein Separation by SCX-MS/MS}

In order to demonstrate the performance of the on-line SCX system, we used a tryptic digest of BSA as a test sample to evaluate the separation performance of this system. A portion of the BSA digest $(950 \mathrm{fmol})$ was injected on the system and SCX separation and data dependent ESI-MS/MS was performed (Figure 2). An optimized gradient (represented by the dashed line, Figure 2) was used for the separation of the peptides. In this experiment, 30 unique peptides from BSA were identified resulting in a sequence coverage of $41 \%$. The ion spray was stable even at $1.0 \mathrm{M}$ ammonium formate. The MS/MS spectrum for the precursor ion with $\mathrm{m} / \mathrm{z}=$ 653.5 resulting from a data dependent experiment is also shown (Figure 2, inset).

The reproducibility of the separation was evaluated by following the retention times of selected ions over four separate experiments (Table 1). The retention times of four ions were extracted from the chromatogram between 16 and $22.5 \mathrm{~min}$. The deviation between sub- 
Table 1. Reproducibility for selected BSA peptides over multiple experiments by on-line SCX-ESI-MS/MS

\begin{tabular}{lcccc}
\hline & \multicolumn{4}{c}{ Retention time (min) } \\
\cline { 2 - 5 } Ion $(\mathrm{m} / \mathrm{z})$ & 653.5 & 820.5 & 789.5 & 886.4 \\
\hline \hline Run 1 & 22.80 & 22.34 & 18.01 & 16.62 \\
Run 2 & 22.69 & 22.13 & 17.69 & 16.19 \\
Run 3 & 22.80 & 22.40 & 17.84 & 16.19 \\
Run 4 & 22.73 & 22.20 & 17.69 & 15.94 \\
Average & 22.76 & 22.27 & 17.81 & 16.24 \\
Relative error & $0.1 \%$ & $0.32 \%$ & $0.50 \%$ & $1 \%$ \\
\hline
\end{tabular}

sequent runs was small with the retention times varying between only 2 to $10 \mathrm{~s}$. In general, the chromatographic peaks examined exhibited a peak width at half height of approximately 10-15 s. These results clearly indicate that reproducible on-line SCX chromatography of peptides is possible.

\section{Effect of the Sample Digest Buffer on the SCX Separation}

Tryptic digestion of protein samples is often performed in an ammonium bicarbonate buffer system. This buffer is expected to be incompatible for direct and effective separation by SCX chromatography because the cationic ammonium ion and the elevated $\mathrm{pH}$ of the buffer ( $\mathrm{pH} \sim 8$ ) will contribute to hinder peptide adsorption to the SCX matrix. Often, the effect of the sample digest buffer is not apparent when standard protein digests are used because these digests are typically performed at high protein concentrations and then diluted significantly prior to analysis, thereby also diluting the buffer components. However, for more realistic samples of interest, the amount of starting material is often low and any further dilution of the sample to facilitate chromatography can become counterproductive. To illustrate this phenomenon, we examined the effect of ammonium bicarbonate concentration on the chromatographic performance. A concentrated tryptic digest of BSA was appropriately diluted into $0.25 \mathrm{M} \mathrm{FA}$ to produce samples containing various final concentrations of ammonium bicarbonate (Figure 3). Chromatography of the digest sample that was loaded containing $50 \mathrm{mM}$ ammonium bicarbonate was accompanied with significant sample loss and band broadening. Sample loss is suspected to be a consequence of the given buffer reducing the capacity of the peptides to bind to the precolumn during sample loading. Noticeable band broadening and sample loss is also observed at $25 \mathrm{mM}$ ammonium bicarbonate. These effects were minimized when the samples contained 5 or $10 \mathrm{mM}$ ammonium bicarbonate. Where observed, the peak broadening appears to be more predominant for those peptides eluting earlier during the gradient. In contrast, no significant peak broadening is observed for peptides eluting later during the gradient (>22.5 min), even at $50 \mathrm{mM}$ ammonium bicarbonate. These observations clearly il- lustrate the need for the careful design of either a one-dimensional SCX or a combined two-dimensional SCX/RP platform. Slight variations in the final concentration of ammonium bicarbonate in the sample, in addition to other potential buffer components, could have drastic effects on the elution profile obtained in the SCX dimension. This can result with detrimental effects for protein identification and quantitation approaches that rely on the analysis of specific SCX fractions obtained from different samples or from multiple runs.

\section{Evaluation of a Step-Gradient Elution by On-Line SCX-MS}

Often, multidimensional chromatography (SCX-RPMS) is obtained by performing a step-gradient elution from the SCX dimension to the RP dimension. This approach precludes direct observation and optimization of the elution profile obtained from the SCX dimension. We used our on-line SCX system to evaluate the effects of a step-gradient on the separation/elution of peptides. Figure 4 illustrates the results obtained from the isocratic elution of peptides from a tryptic digest of BSA (950 fmol) using different concentrations of ammonium formate. When $50 \mathrm{mM}$ ammonium formate, $0.25 \mathrm{M}$ FA was used as the mobile phase, only six major chromatographic components are observed. In comparison, approximately 9-10 distinct chromatographic components are observed when the mobile phase concentration of ammonium formate is increased to 100 or $150 \mathrm{mM}$ (Figure 4). Furthermore, the retention times of peptides that demonstrate a weak interaction with the SCX material and are eluted "early" in the run (between approximately 15-18 min under each condition) appeared to be unaffected by the ammonium formate concentration. In contrast, the retention times and peak shapes of peptides having increased interaction with the SCX phase and that elute "late" in the run showed a greater dependency. This indicates that desorption of a given peptide is dependent on both the concentration of the salt but also, on the duration of the isocratic elution. Consequently, it would appear that any peptide, regardless of its strength of interaction with the SCX resin, can be eluted at a given salt concentrations if the mobile phase is applied for extended times. However, and in particular for stronger interacting peptides, peptide desorption will be accompanied by peak broadening. This is an important consideration for an on-line SCX-RP system in which both the salt concentration of the step-gradient buffer used as well as the length of time that the buffer is applied will affect the elution profile of peptides.

\section{Correlation Between Peptide Isolelectric Point and Retention Time}

We analyzed the elution profiles obtained from SCX-MS analysis of BSA and phosphorylase-b tryptic 


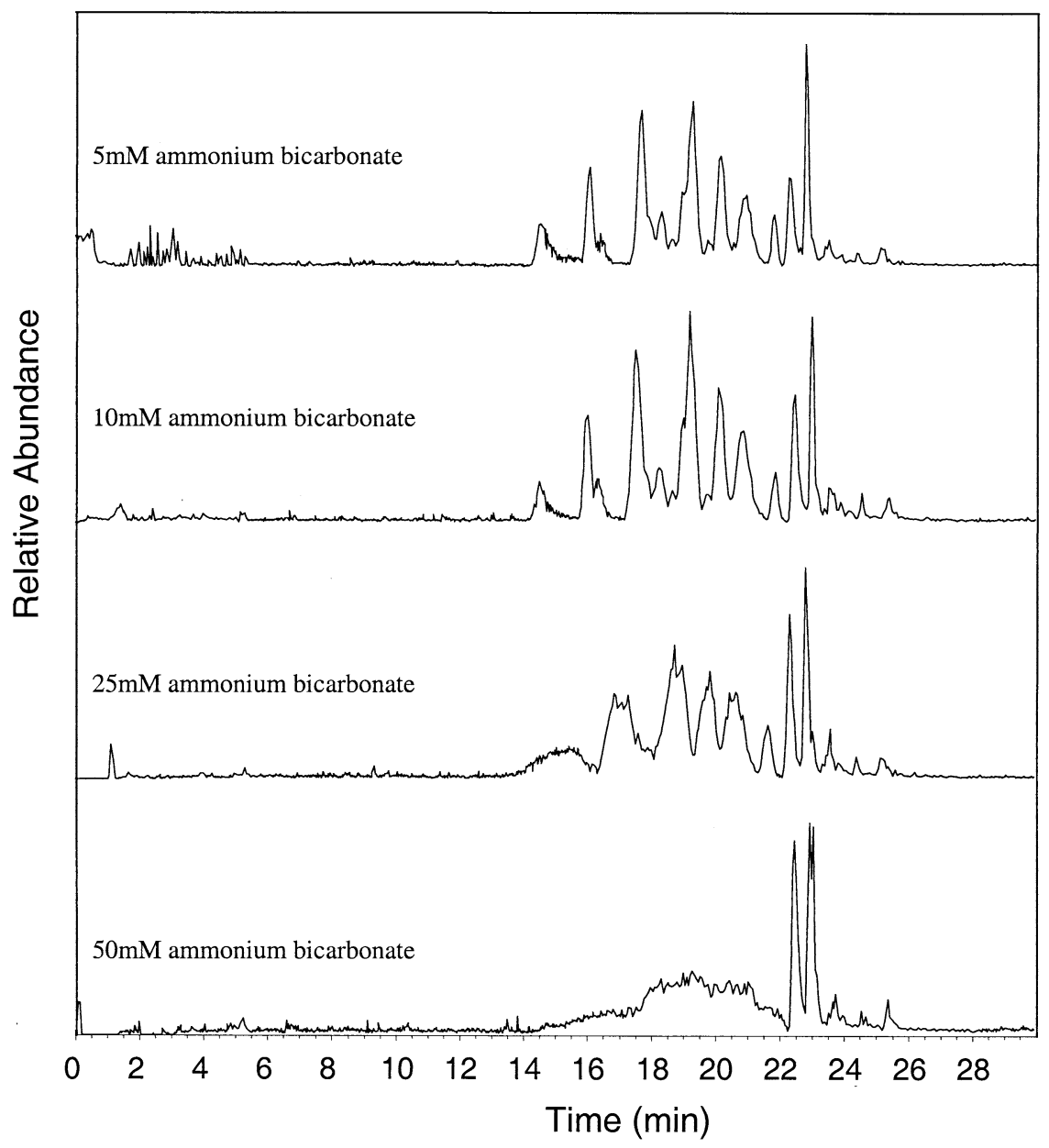

Figure 3. Effect of ammonium bicarbonate concentration on SCX chromatographic behavior. Shown are the base peak chromatograms obtained from SCX-MS analysis of a BSA tryptic digest (950 fmol) in sample buffers containing various concentrations of ammonium bicarbonate (as indicated). The column geometry and gradient conditions used are described in the legends to Figures 1 and 2, respectively.

digests. A plot of the measured retention time versus the calculated isoelectric point $(p \mathrm{I})$ of each peptide (as determined using the Bjellqvist algorithm [18]) revealed a trend (Figure 5). Peptides with $p$ I values below 6 exhibited a relation between their $p \mathrm{I}$ and their retention time, with the retention time increasing with increasing $p \mathrm{I}$. Little to no dependency on retention time is observed for peptides having a $p \mathrm{I}$ greater than 6 . In a parallel experiment, the same BSA and phosphorylase-b digests were also analyzed by RP-MS. No obvious trend was observed between the retention time in RP and the retention time in SCX (result not shown).

\section{Limit of Detection for SCX-ESI-MS/MS}

We have evaluated the limit of detection (LOD) that can be achieved using SCX- MS using the optimized separation protocol. In this case, we have defined the LOD as the lowest quantity of a protein digest that can be analyzed and provide identification of the protein from a database search. In several respects, this is a more meaningful determination of the LOD for proteomic studies. A series of experiments were performed by loading different absolute amounts of the phosphorylase $b$ tryptic digest. The compiled MASCOT results were plotted against the amount of phosphorylase $b$ loaded on the column (Figure 6a). Interestingly, a clear relationship exists between the MASCOT score and the absolute amount of phosphorylase $b$ subjected to analysis. The same relationship also exists between the number of peptides identified. These observations suggest that an approach based on peptide identification or the resulting compiled score could be used as a semi-quantitative tool for determining protein levels in a mixture. The lowest amount of phosphorylase $b$ that was sufficient for identification through MASCOT was 17 fmol. This is comparable with results routinely obtained with RP-MS strategies. 


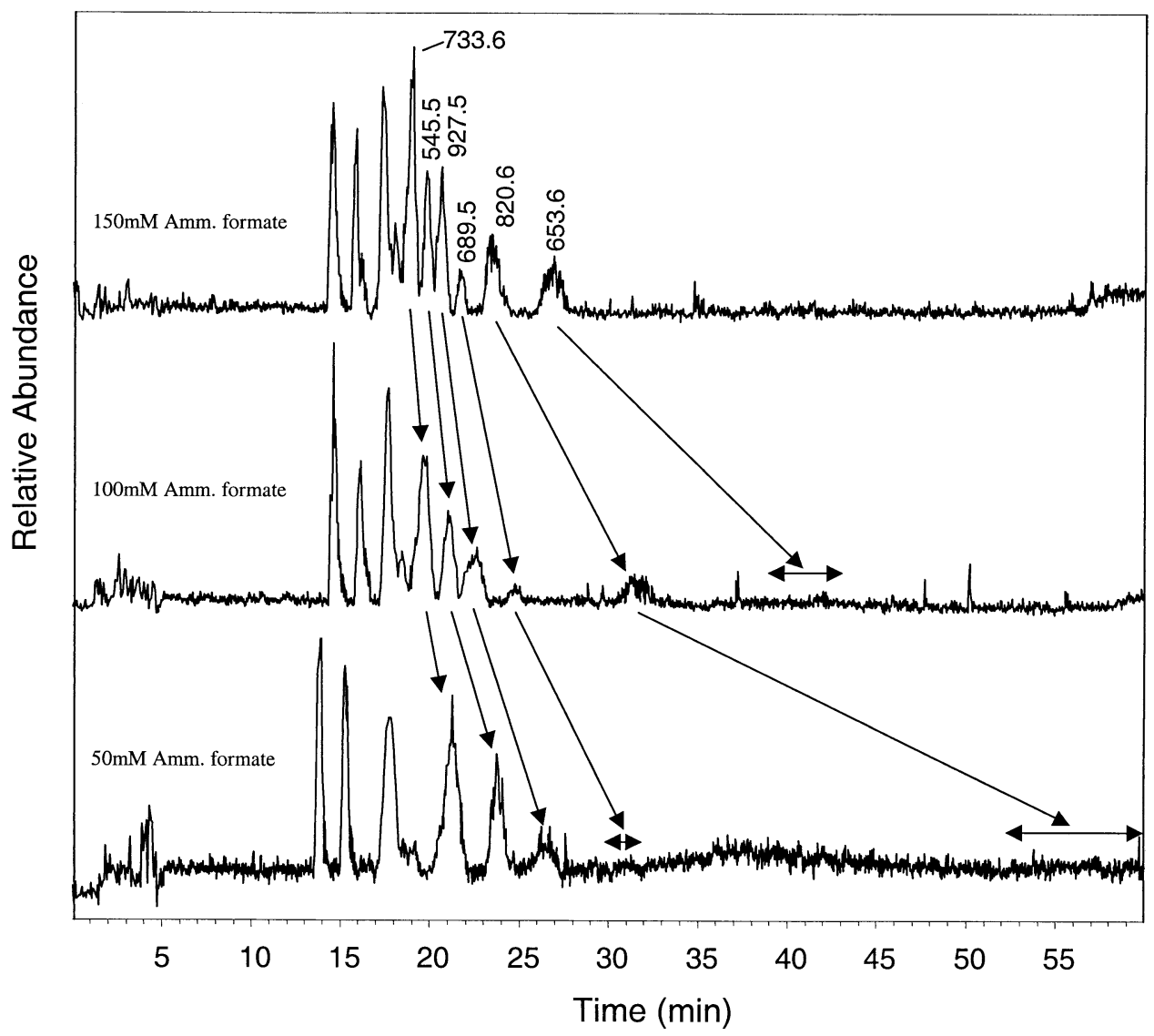

Figure 4. Base peak chromatograms obtained from the SCX-MS analysis of a BSA tryptic digest (950 fmol) subjected to isocratic elution with mobile phases containing different concentrations of ammonium formate (as indicated) in $0.25 \mathrm{M} \mathrm{FA}$. The column geometry and gradient conditions used are described in the legends to Figures 1 and 2, respectively.

\section{Comparison Between On-Line SCX and On-Line RP for a Complex Sample}

The performance of on-line SCX-MS/MS and RPMS/MS was compared in terms of profiling a complex sample. Total protein was isolated from human K562 cells, digested with trypsin and a portion of the digest

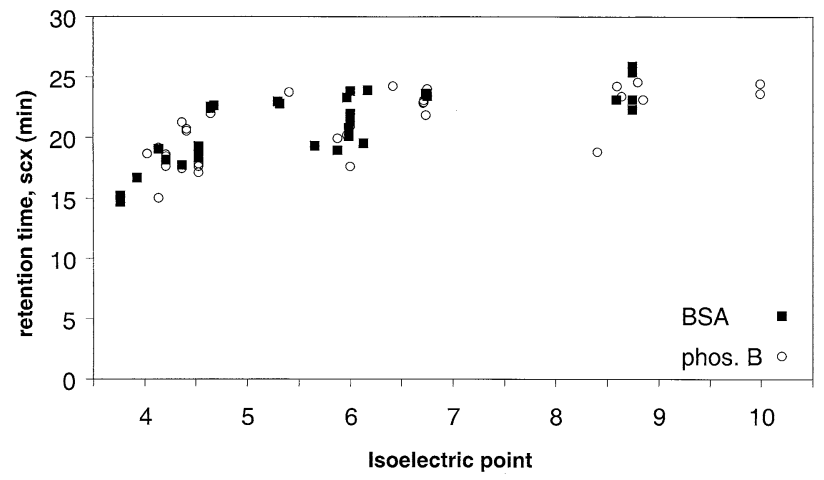

Figure 5. Retention time of peptides from tryptic digests of BSA (filled square) and phosphorylase $\mathrm{b}$ (open circle) separated by on-line SCX-MS versus their theoretical isoelectric points. The column geometry and gradient conditions used are described in the legends to Figures 1 and 2, respectively. equivalent to the amount of protein obtained from 2.2 $\times 10^{4}$ cells $(2 \mathrm{ug})$, was analyzed by each method. The top 25 proteins hits identified from each method, as ranked by their MASCOT score, are presented in Table 2. While the majority of the top 10 proteins identified from one method were also identified by the other method (but of different ranking), several proteins identified were unique to each. For example, the dnaK-type chaperone was identified with a ranking of 5 by RP-MS but was not in the top 25 proteins identified by SCX-MS. Similarly, polypeptidyl-tRNA translocase and cyclophilin A, identified with rankings of 9 and 10, respectively, by SCX-MS were not in the top 25 hits as determined by RP-MS. In addition, the number of peptides associated with each protein identified by the on-line SCX method is less than that determined by on-line RP.

Several reasons may account for the difference in peptide and protein identification by the two methods. One is simply the fact that in complex samples of this nature, only a small fraction of peptides present will be selected for MS/MS because of inherent limitations associated with data dependent experiments. We have routinely observed that the overlap in peptides identi- 


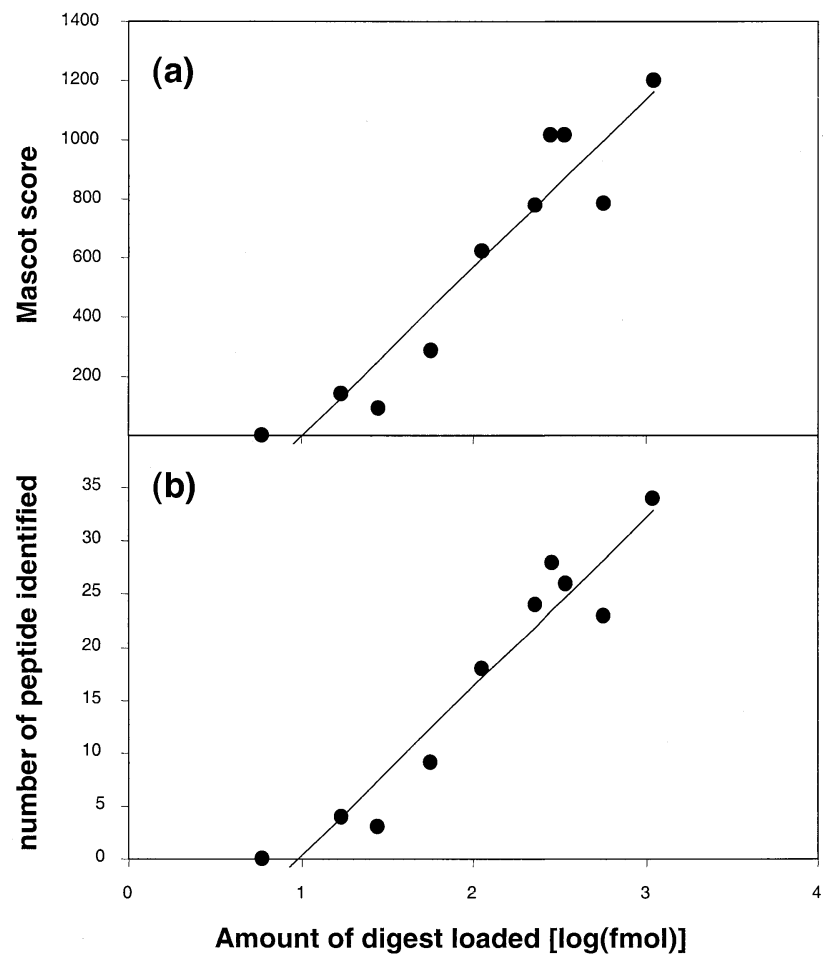

Figure 6. Limit of detection (LOD) by SCX-MS/MS. The LOD was determined using incremental absolute amounts of a tryptic digest of phosphorylase $b$ (from 5 to $1100 \mathrm{fmol}$ ). Positive identification of phosphorylase $b$ was achieved at all levels above $17 \mathrm{fmol}$. The MASCOT score (a) and the number of peptides identified (b) are plotted as a function of the log of the amount of the digested loaded. fied between multiple analyses of the same sample is approximately $60-80 \%$ by either SCX-MS or RP-MS. Moreover, as described earlier and as is to be expected for chromatography over different solid phases, there was no observable correlation between the retention times for peptides separated on SCX and RP. Therefore, at any given time during chromatography by either method, the population of peptides and hence, the relative abundance of a particular ion to other ions present in the survey scan at that time will be different. This will affect the likelihood of a peptide to be selected for MS/MS.

The difference in identification noted above may also arise from the observation that SCX-MS and RP-MS tend to favor identification of peptides depending on their average molecular weight. As illustrated in Figure 7, both SCX-MS and RP-MS produce an asymmetric distribution when relating the total number of peptides identified to the length of the peptide. The distribution for RP-MS reveals a maximum between 8-12 residues. In contrast, SCX-MS produced a maximum distribution for peptides having 14-18 residues (Figure 7a). For all peptides identified, the average residue length identified by RPand SCX-MS was 13 and 15.4, respectively (Figure $7 b)$. These results suggest that higher molecular weight peptides are more likely to be identified by SCX-MS than by RP-MS and illustrate the complementary coverage that can be achieved by combining both methods.

Table 2. Top 25 proteins identified by capillary LC-RP-MS and LC-SCX-MS from a complex protein digest derived from human K562 cells

\begin{tabular}{|c|c|c|c|c|c|c|}
\hline Rank & RP-MS protein name & $\mathrm{Gi}$ & No. pept. & SCX-MS protein name & $\mathrm{Gi}$ & No. pept. \\
\hline 1 & $90 \mathrm{kDa}$ heat shock protein & gi306891 & 20 & $90 \mathrm{kDa}$ heat shock protein & gi306891 & 8 \\
\hline 2 & $70 \mathrm{kDa}$ heat shock protein & gi11526573 & 15 & $\beta$ tubulin & gi897763 & 9 \\
\hline 3 & $\beta$ tubulin & gi897763 & 11 & 2-Phosphopyruvate-hydratase & gi693933 & 5 \\
\hline 4 & $\gamma$ actin & gi7441428 & 13 & $\gamma$ actin & gi7441428 & 6 \\
\hline 5 & dnaK-type molecular chaperone & gi2119712 & 9 & Elongation factor $1-\alpha$ & gi31092 & 5 \\
\hline 6 & 2-phosphopyruvate-hydratase & gi693933 & 8 & Histone $\mathrm{H} 1-2$ & gi2144736 & 6 \\
\hline 7 & $78 \mathrm{kDa}$ glucose regulated protein prec. & gi14916999 & 7 & $\alpha$ tubulin & gi37492 & 5 \\
\hline 8 & $\alpha$ tubulin & gi37492 & 8 & Aldolase A & gi28597 & 6 \\
\hline 9 & Elongation factor $1-\alpha$ & gi31092 & 7 & Polypeptidyl-tRNA translocase & gi4503483 & 5 \\
\hline 10 & Histone $\mathrm{H} 1$ & gi22770669 & 6 & Cyclophilin A & gi1000027 & 4 \\
\hline 11 & Mortalin-2 & gi12653415 & 6 & $70 \mathrm{kDa}$ heat shock protein & gi11526573 & 4 \\
\hline 12 & Nucleosphosmin & gi825671 & 3 & Histone $\mathrm{H} 2 \mathrm{~B}$ & gi22770657 & 4 \\
\hline 13 & $60 \mathrm{kDa}$ heat shock protein & gi129379 & 5 & Glyceraldehyde-3-phosphate deH $_{2}$ & gi31645 & 3 \\
\hline 14 & Histone $\mathrm{H} 2 \mathrm{~B}$ & gi22770657 & 6 & Serine hydroxymethyltransferase & gi703093 & 2 \\
\hline 15 & hnRNP B1 protein & gi337453 & 5 & Histone $\mathrm{H} 2 \mathrm{~A}$ family & gi3493529 & 2 \\
\hline 16 & Peptidylpropyl isomerase & gi68400 & 4 & Ribosomal protein & gi20810536 & 2 \\
\hline 17 & Protein $\mathrm{A} 1-\alpha$ & gi36102 & 3 & Multifunctional purine biosynthesis proteir & gi106347 & 2 \\
\hline 18 & Histone H3.1 & gi1070597 & 4 & Talin & gi4235275 & 2 \\
\hline 19 & Aldolase $\mathrm{A}$ & gi28597 & 4 & ATP synthase & gi16741373 & 2 \\
\hline 20 & heterogenous ribonuclear particle & gi284156 & 3 & Bip protein & gi6470150 & 2 \\
\hline 21 & Nucleolin & gi4885511 & 4 & heterogenous ribonuclear particle protein & gi87653 & 2 \\
\hline 22 & Heterogenous nuclear ribonucleoprot. & gi12653175 & 3 & Elongation factor $1-\gamma$ & gi14602684 & 2 \\
\hline 23 & Triosephosphate isomerase & gi136066 & 3 & peroxiredoxin & gi4505591 & 3 \\
\hline 24 & KIAA002 & gi286011 & 2 & Pro-ubiquitin & gi340062 & 3 \\
\hline 25 & Ribosomal protein S3A & gi14424796 & 3 & PTB-associated splicing factor & gi38458 & 2 \\
\hline
\end{tabular}




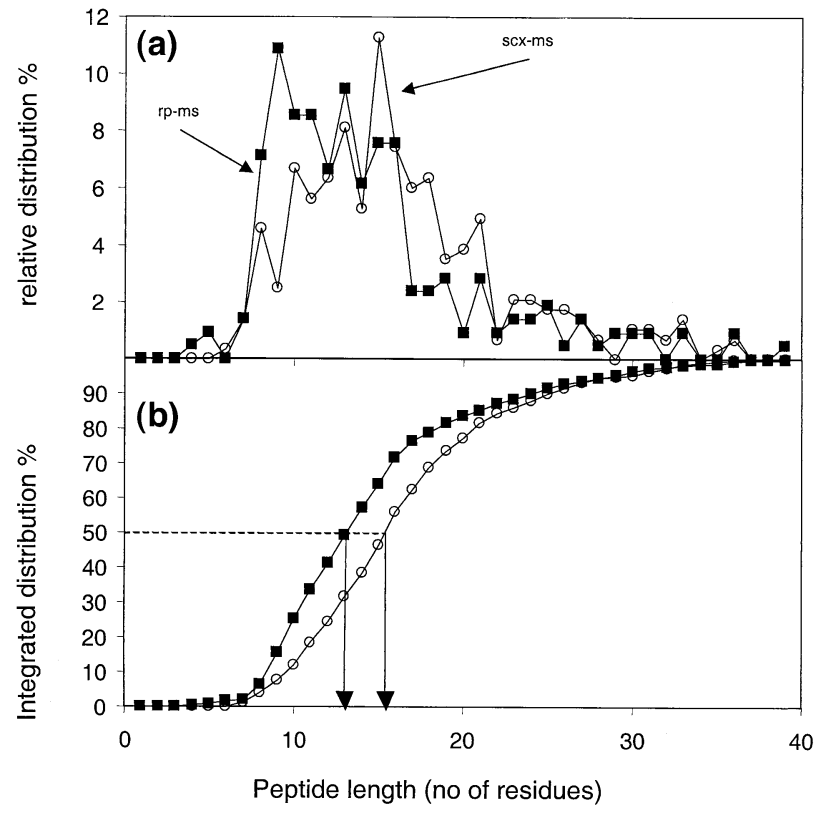

Figure 7. Comparison of the distribution in peptide length identified by SCX-MS (open circle) and RP-MS (filled square) from the analysis of a complex protein digest derived from human K562 cells $\left(2.2 \times 10^{4}\right.$ cell equivalents). The relative distribution (a) and the cumulative distribution (b) are plotted as a function of the length of the peptide.

\section{Conclusion}

In this preliminary report, we demonstrate for the first time that on-line SCX-MS/MS is a robust method for routine proteomics studies. In addition, we have shown that on-line SCX-MS is useful for determining optimal conditions for multidimensional separations, such as appropriate sample preparation to ensure superior chromatographic performance. Finally, we have established that SCX-MS/MS provides complimentary information to RP-MS/MS. Consequently, the methodology presented herein should provide researchers with an alternate approach that has been traditionally dominated by RP-MS.

\section{References}

1. Gygi, S. P.; Rochon, Y.; Franza, B. R.; Aebersold, R. Correlation Between Protein and mRNA Abundance in Yeast. Mol. Cell. Biol. 1999, 19, 1720-1730.

2. Mann, M.; Hendrickson, R. C.; Pandey, A. Analysis of Proteins and Proteomes by Mass Spectrometry. Annu. Rev. Biochem. 2001, 70, 437-473.

3. Santoni, V.; Molloy, M.; Rabilloud, T. Membrane Protein and Proteomics: Un Amour Impossible? Electrophoresis 2000, 21, 1054-1070.
4. Wu, C. C.; Yates, J.R., III. The Application of Mass Spectrometry to Membrane Proteins. Nat. Biotech. 2003, 21, 262-267.

5. Arnott, D.; Kishiyama, A.; Luis, E. A.; Ludlum, S. G.; Marsters, J. C.; Stults, J. T. Selective Detection of Membrane Proteins Without Antibodies. Mol. Cell Proteomics 2002, 1, 148-156.

6. Blonder, J.; Goshe, M. B.; Moore, R. J.; Pasa-Tolic, L.; Masselon, C. D.; Lipton, M. S.; Smith, R. D. Enrichment of Integral Membrane Proteins for Proteomic Analysis Using Liquid Chromatography-Tandem Mass Spectrometry. J. Proteome Res. 2002, 1, 351-360.

7. Verma, R.; Chen, S.; Feldman, R.; Schieltz, D.; Yates, J.; Dohmen, J.; Deshaies, R. J. Proteasomal Proteomics: Identification of Nucleotide-Sensitive Proteasome-Interacting Proteins by Mass Spectrometric Analysis of Affinity-Purified Proteasomes. Mol. Biol. Cell 2000, 11, 3425-3439.

8. Optiteck, G. J.; Ramirez, S. M.; Jorgenson, J. W.; Moseley, M. A. I. Comprehensive Two-Dimensional High-Performance Liquid Chromatography for the Isolation of Over-Expressed Protein and Protein Mapping. Anal. Biochem. 1998, 258, 349361.

9. Link, A. J.; Eng, J.; Schieltz, D. M.; Carmack, E.; Mize, G. J.; Morris, D. R.; Garvik, B. M.; Yates, J. R., III. Direct Analysis of Protein Complexes Using Mass Spectrometry. Nat. Biotechnol. 1999, 17, 676-682.

10. Washburn, M. P.; Wolters, D.; Yates, J. R., III. Large-Scale Analysis of the Yeast Proteome by Multidimensional Protein Identification Technology. Nat. Biotechnol. 2001, 19, 242-247.

11. Peng, J.; Elias, J. E.; Thoreen, C. C.; Licklider, L. J.; Gygi, S. P. J. Evaluation of Multidimensional Chromatography Coupled with Tandem Mass Spectrometry (LC/LC-MS/ MS) for Large-Scale Protein Analysis: The Yeast Proteome, unpublished.

12. Huber, C. G.; Buchmeiser, M. R. On-Line Cation Exchange for Suppression of Adduct Formation in Negative-Ion Electrospray Mass Spectrometry on Nucleic Acids. Anal. Chem. 1998, 70, 5288-5295.

13. Wu, L. C. Isolation and Long-Term Storage of Proteins from Tissues and Cells Using TRIzol Reagent. Focus 1995, 13, 98-100.

14. Zhang, X.; Huang, S. Single Step On-Column Frit Making for Capillary High-Performance Liquid Chromatography Using Sol-Gel Technology. J. Chromatogr. A 2001, 910, 13-18.

15. Licklider, L. J.; Thoreen, C. C.; Peng, J.; Gygi, S. P. Automation of Nanoscale Micocapilary Liquid Chromatography-Tandem Mass Spectrometry with a Vented Column. Anal. Chem. 2002, 74, 3076-3083.

16. Perkins, D. N.; Pappin, D. J.; Creasy, D. M.; Cottrel, J. S. Probability-Based Protein Identification by Searching Sequence Databases Using Mass Spectrometry Data. Electrophoresis 1999, 20, 3551-3567.

17. Corthals, G. L.; Wasinger, V. C.; Hochstrasser, D. F.; Sanchez, J.-C. The Dynamic Range of Protein Expression: A Challenge for Proteomic Research. Electrophoresis 2000, 21, 1104-1115.

18. Bjellqvist, B.; Hughes, G. J.; Pasquali, C.; Paquet, N.; Ravier, F.; Sanchez, J.-C.; Frutiger, S.; Hochstrasser, D. F. The Focusing Positions of Polypeptides in Immobilized pH Gradients Can Be Predicted from Their Amino Acid Sequences. Electrophoresis 1993, 14, 1023-1031. 